\title{
MULTI-CRITERIA RESERVOIR WATER MANAGEMENT
}

\author{
K. HADJIBIROS* \\ A. KATSIRI \\ A. ANDREADAKIS \\ D. KOUTSOYIANNIS \\ A. STAMOU \\ A. CHRISTOFIDES \\ A. EFSTRATIADIS \\ G. SARGENTIS
}

Selected from papers presented in $9^{\text {th }}$

International Conference on Environmental

Science and Technology (9CEST2005)

1-3 September 2005, Rhodes island, Greece

\author{
Department of Water Resources \\ National Technical University of Athens \\ 5, Iroon Polytechniou str. \\ 15780, Zografou, Athens, Greece
}

\begin{abstract}
The Plastiras dam was constructed in the late 1950s mainly for electric power production, but it has also partially covered irrigation needs and water supply of the plain of Thessaly. Later, the site has been designated as an environment conservation zone because of ecological and landscape values, while tourist activities have been developed around the reservoir. Irrigation of agricultural land, hydroelectric production, drinking water supply, tourism, ecosystem water quality and scenery conservation have evidently been conflicting targets for many years. Good management would require a multi-criteria decision making.

Historical data show that the irregular water release has resulted in a great annual fluctuation of the reservoir water level. This situation could be improved by a rational management of abstractions. Apparently, higher release leads simultaneously to more power production and to irrigation of a larger agricultural land. Moreover, demands for electricity and for irrigation are partially competing to each other, due to different optimal time schedules of releases. On the other hand, higher water release leads to lower water level in the reservoir and, therefore, it decreases the beauty of the scenery and deteriorates the trophic state of the lake. Such degradation affects the tourist potential as well as the quality of drinking water supplied by the reservoir.
\end{abstract}

A multi-criteria approach uses different scenarios for the minimum permissible water level of the reservoir, if a constant annual release is applied. The minimum level concept is a simple and functional tool, because it is understood by people, easily certified and incorporated into regulations. The quantity of water that would be yearly available is a function of the minimum level allowed. The water quality depends upon the trophic state of the lake, mainly the concentration of chlorophyll-a, which determines the state of eutrophication and is estimated by water quality simulation models, taking into account pollutant loads such as nitrogen and phosphorus. The value of the landscape is much depending on the water level of the lake, because for lower levels a dead-zone appears between the surface of the water and the surrounding vegetation. When this dead zone is large, it seems lifeless and the lake appears partially empty. Quantification of this visual effect is not easy, but it is possible to establish a correspondence between the aesthetic assessment of the scenery and the minimum allowed reservoir level. 
Using results from hydrological analysis, water quality models and landscape evaluation, it seems possible to construct a multi-criteria table with different criteria described against alternatives and with a plot of three relative indices against the minimum level allowed. However, decision making has to take into account the fact that comparison or merging of indices corresponding to different criteria analysis encompasses a degree of arbitrariness. More objective decisions would be possible if different benefits and costs were measured in a common unit. Moreover, management will be sensitive to different social pressures.

KEYWORDS: water release, landscape quality, water quality, minimum level, rational management, water supply, irrigation, tourism, hydroelectric production.

\section{INTRODUCTION}

The Plastiras reservoir has been created in late 1950s, with the construction of an arch dam on the river Tavropos, in the mountains of Central Greece. Tavropos is a tributary of river Acheloos, one of the biggest rivers of Greece, flowing from the mountains of North West and Central Greece to the Ionian Sea. The river Tavropos has been diverted to the East and, after a chute of $577 \mathrm{~m}$, the water flows in the Thessaly plain. The main purpose of that project has been hydroelectric energy generation, a secondary purpose being, from the beginning, irrigation for agricultural needs.

During the '80s, irrigation needs have increased, because of intensive agricultural development of Thessaly, following support from European Common Agricultural Policy. Water release from the reservoir has been always controlled by the Public Power Corporation (PPC), but gradually was adapted to agricultural demand, given that the hydroelectric potential and the importance of the reservoir relatively to the energy needs of Greece were decreasing. A small portion of the lake water has been also used for supply of the increasing urban needs of plain settlements. At the same period, the artificial lake and the surrounding landscape was developed into area with environmental interest, both from the ecological and the aesthetic point of view.

During the 1990s, this area has attracted an increasing number of tourists, mainly from Greek cities, both in summer and in winter months. The area has also been included in the Natura 2000 list of European conservation zones and classified as a Site of Outstanding Natural Beauty (FILOTIS 2003). A number of hotels and other tourist infrastructure have been built; activities related to the accommodation and the recreation of visitors have led this poor mountain area to a significant economic development. The socioeconomic evolution is still continuing and the economic importance of different water uses is changing. According to actual tendencies, the economic feed back of water uses for drinking, tourism and environmental conservation is growing, while for agriculture and electricity production is getting down.

The change of economic realities does not automatically lead to change of the water management priorities because delays of social origin play an important role. The PPC but mainly the local agricultural trade unions are resistant to the establishment of a water management that should prioritize other uses. Since the late 1990s, disputes over the reservoir water exploitation have been frequent; very intense in dry years, they were partially forgotten when rainfall or snow have been abundant. The reservoir management, always controlled by the PPC, has been subjected to strong pressures from agricultural lobbies and, as a result, it had little to do with a scientific approach according to hydrological, hydroelectric, environmental, economic or regional development criteria (Research group 2002). 


\section{METHODOLOGY}

\section{Analysis of conflicts and impacts between water uses}

Different possible uses of the reservoir interact, creating mutual influences (Figure 1). Therefore, the uses and the relative positive and negative impacts form a complex system, which is analyzed in Table 1.

The water abstraction for irrigation causes a significant decrease of the water level and of the lake volume. The value of the landscape is much depending on the water level, because for lower levels a dead-zone appears along the lake shores between the surface of the water and the surrounding vegetation (Sargentis et al 2005a). When this dead zone is large, it seems lifeless and the lake appears partially empty. Thus, a strong impact is created by the irrigation on the aesthetic value of landscape and the related tourist development perspectives, especially during dry summer months when the environment and the related tourist activities are more vulnerable. The water abstraction for hydroelectric energy production also creates a strong impact on the landscape quality and the tourist development. Even though the irrigation water is the same that produces energy, there is a significant conflict between the two uses; if the water release follows an energy-efficient schedule, then the agricultural water needs are not satisfied at the right time and volume; if the water release is dictated by the irrigation needs, as it has happened since the 1980 s, then energy production is reduced to a side-effect of lower economic value.

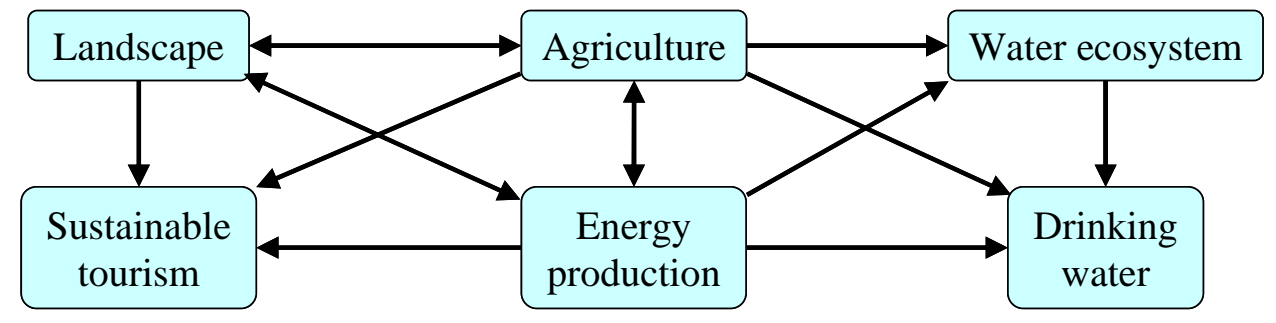

Figure 1. Main interactions between water uses of the Plastiras reservoir

The water quality depends upon the trophic state of the lake, mainly the concentration of chlorophyll-a, which determines the tendency of the lake to pass from oligotrophic to mesotrophic condition; this is estimated by water quality simulation models (Research group 2002, Hadjibiros et al 2002, Andreadakis et al 2003), taking into account certain pollutant loads such as nitrogen and phosphorus. The water abstraction for irrigation or for energy production has a negative impact on the lake water quality and, consequently, may significantly decrease the quality of drinking water. A similar result may be produced by liquid or solid waste disposed in the lake from uncontrolled tourist activities. Such activities will also harm landscape quality as well as sustainable tourist development.

Emphasis put on landscape conservation would constitute a significant limiting factor for high water release, especially when the inflow to the lake is low. Thus, water use for irrigation or energy production would be restricted, if a high water level was maintained; in that case, water and landscape quality would be higher, producing positive impacts on the drinking water quality and on the tourist development respectively.

\section{Framework of a rational management}

Evidently, the conflicts between different water uses lead to impasses if each part insists to maximize profits produced by the water use it prefers. Mutual compromises are necessary, in order that the whole question is conducted to a rational management optimizing common benefits (Popper 1945). The solution has to be based upon scientific and technological expertise and supported by argumentation on the necessity of saving natural resources and accepting compromises. 
Table 1. Negative and positive influences between different uses

The meaning of the symbols: $(-,+)$ indicate negligible impacts, $(--,++)$ significant impacts and $(---,+++)$ strong impacts, negative or positive respectively

\begin{tabular}{|l|l|l|l|l|l|l|}
\hline $\begin{array}{c}\text { Direction of } \\
\text { the influence } \\
\rightarrow\end{array}$ & $\begin{array}{c}\text { Energy } \\
\text { production }\end{array}$ & Irrigation & $\begin{array}{c}\text { Drinking } \\
\text { water }\end{array}$ & $\begin{array}{c}\text { Sustainable } \\
\text { tourism }\end{array}$ & $\begin{array}{c}\text { Water } \\
\text { quality }\end{array}$ & $\begin{array}{l}\text { Landscape } \\
\text { quality }\end{array}$ \\
\hline $\begin{array}{l}\text { Energy } \\
\text { production }\end{array}$ & $\S$ & -- & -- & --- & -- & --- \\
\hline Irrigation & -- & $\S$ & -- & --- & -- & --- \\
\hline $\begin{array}{l}\text { Drinking } \\
\text { water }\end{array}$ & - & - & $\S$ & & & \\
\hline $\begin{array}{l}\text { Uncontrolled } \\
\text { tourism }\end{array}$ & & & -- & -- & - & -- \\
\hline $\begin{array}{l}\text { Water } \\
\text { quality }\end{array}$ & - & - & +++ & + & $\S$ & \\
\hline $\begin{array}{l}\text { Landscape } \\
\text { quality }\end{array}$ & -- & -- & & +++ & & $\S$ \\
\hline
\end{tabular}

An important step towards this direction is the implementation of recent legislation, particularly the EU directives 2000/60 on water management and 92/43 on natural habitat conservation.

The first one imposes the quality classification of water bodies and the second one establishes the Natura 2000 conservation zones system, which the Plastiras lake is a part of. According to experts (Research group 2002), the instruments for a rational management of the reservoir have to be the following:

- Establishment of a minimum water level allowed

- Constant annual water release (reliability 90\%)

- Maintain level rather than release in case of failure (probability 10\%)

- Constant monitoring of water level and of water and landscape quality

- Measures for protection or rehabilitation of the riparian landscape pressed by uncontrolled tourist development.

The quantity of water that would be yearly available is a function of the minimum level allowed. The minimum level concept is a simple and functional tool, because it is understood by people, easily certified and incorporated into regulations. The main difficulties for the implementation of a rational management are the social pressures, principally from local short-term rural interests, as well as the uncertainties about the physical or socioeconomic context.

\section{Identification of important parameters}

The uses of irrigation and hydroelectric production may be in conflict between them relatively to the timing of water abstractions, but they are both represented by the total annual water release, that constitutes a management parameter. The tourist use and the drinking water supply fit with the landscape and the water quality that both may constitute management parameters. The uncontrolled tourism is a parameter that has only negative impacts, even on the sustainable tourist development and it has to be excluded from a rational management. Therefore, the parameters that operate independently and have to be examined together in order to define the management are three: water release, water quality and landscape quality. 


\section{Evaluation and quantification of environmental impacts}

The negative environmental impacts due to the absence of a rational reservoir management are manifested on the landscape and on the water quality. Quantification of the landscape quality alteration is difficult, given the subjective nature of aesthetic assessments. The development of suitable tools and the relative impact assessment based on the size of the dead-zone are examined by Sargentis et al (2005b) and by Sargentis et al (2005a) respectively. The evaluation procedure (Research group 2002) establishes a correspondence between some critical values of the lake's level and qualitative landscape assessments (Table 2). The whole approach can be considered:

- Objective to the extend it represents the opinion of a significant number of observers and the impact depends on the size of dead-zone.

- Arbitrary to the extend that the aesthetic assessments are transformed into quantified impacts, having the form of percentages (linear approach).

Table 2. Correspondence between minimum level allowed and landscape or water quality

\begin{tabular}{|l|l|l|}
\hline Minimum level allowed & Landscape quality & Water quality \\
\hline $790 \mathrm{~m}$ & excellent & (not estimated) \\
\hline $788 \mathrm{~m}$ & very good & (not estimated) \\
\hline $786 \mathrm{~m}$ & altered but good & very good \\
\hline $784 \mathrm{~m}$ & acceptable & good \\
\hline $782 \mathrm{~m}$ & just tolerated & acceptable \\
\hline $780 \mathrm{~m}$ & not acceptable & fair \\
\hline
\end{tabular}

Quantification of the water quality alteration is possible, based on the calculation of important parameters like chlorophyll-a and dissolved oxygen. The time fluctuation of chlorophyll-a concentrations for a few values of the reservoir minimum permissible level is calculated with the use of simulation models. Notable differences in the expected maximum annual summer chlorophyll-a concentrations for the alternative management scenarios have been observed (Andreadakis et al 2003). Taking account of the maximum chlorophyll-a concentrations estimated for each level, in combination with the EU classification systems for lake quality, a correspondence between minimum permissible level and environmental impact on water quality is established (Table 2). The whole approach can be considered:

- Objective to the extend that the mathematical models used constitute an effective representation of water quality.

- Arbitrary to the extend that the assumption of a fully mixed state of the lake and the transformation of classification system categories in percentages of impact (linear approach) may be disputed.

\section{Evaluation and quantification of impacts on productive activities}

Negative impacts from a management based on a minimum permissible level may be manifested on the agricultural and on the energy production, because of limitation of water releases. Quantification of the impact on agriculture is possible, given that the value of the safe annual release and the corresponding reliability for every minimum permissible level is calculated by hydrological models (Research group 2002). The result is the possibility of water release as a function of the minimum permissible level for a given reliability. This approach can be considered:

- Objective, given that the quantities of water are represented accurately.

- Arbitrary to the extend that the relation of the quantity of water for irrigation to the subsequent increase in value of the agricultural production remains uncertain.

Quantification of the impact on energy production is based on the calculation of the precise quantity and value of electricity produced as a function of the minimum permissible level and the rate of water release. This approach can be considered: 
- Objective to the extend that its computational part is precise.

- Arbitrary to the extend that the regime of water release is usually not determined by energy needs but by external factors.

The negative impact on the hydroelectric use is finally not considered; the future management will depend on other priorities, given that the use of the reservoir for energy production is not important any more.

\section{Transformation of criteria to indices}

Based on the above impact analysis, the change of each one of the three selected parameters, that is safe release, water quality and landscape quality can be expressed in a scale from 0 to 1 . Number 0 corresponds to a very big impact which is not acceptable, while number 1 corresponds to an impact small enough to be acceptable without reservation. The mathematical expression of these three indices is created by linear transformation and linear interpolation of intermediate values in the cases of the safe release and the water quality. For the quantification of the landscape quality criterion, the transformation has been somewhat more complicated, given that the time distribution of different water levels in relation to the minimum permissible level $\mathrm{z}$ had also to be taken into account. The time distribution has been calculated by the reservoir hydrological model, through a stochastic simulation. The values of landscape quality indices have been calculated by the equation (Research group 2002):

$$
I(z)=0.25 \times p_{1}(z)+0.50 \times p_{2}(z)+0.75 \times p_{3}(z)+1.00 \times p_{4}(z)
$$

where $p_{1}, p_{2}, p_{3}$ and $p_{4}$ the frequencies of level below $+782 \mathrm{~m},+784 \mathrm{~m},+786 \mathrm{~m}$ and +788 $\mathrm{m}$ respectively. By definition, the index of landscape quality has been considered equal to 0 when the minimum permissible level is established at $+776 \mathrm{~m}$.

\section{Decision tools}

In multi-criteria decision analysis, rational decisions are taken through maximization of some utility function. The selection of the three parameters that will constitute the criteria and of their weighted role in the utility function will indicate an optimal choice of the minimum permissible level. Different combinations have been examined, where the criteria:

- Are considered to be equivalent, putting the weight coefficients equal to 1.

- One of the criteria is superior, putting its weight coefficient equal to 2.

- There is strong superiority of one criterion, putting its weight coefficient equal to 4 . Finally, the utility function is expressed as the weighted sum of the three indices $I_{1}, I_{2}, I_{3}$ with use of the weight coefficients $w_{1}, w_{2}, w_{3}$ :

$$
F=w_{1} I_{1}+w_{2} I_{2}+w_{3} I_{3}
$$

\section{RESULTS}

Figure 2 shows the variation of the indices corresponding to the safe release, the water quality and the landscape quality in relation to the minimum level allowed. The range of values for the minimum level allowed has been considered from $+776 \mathrm{~m}$ (water uptake level) to $+790 \mathrm{~m}$ ( $2 \mathrm{~m}$ below overflow level).

Multi-criteria analysis (Hipel 1992, Research group 2002) has indicated the minimum permissible level of $+785 \mathrm{~m}$ to be the choice that maximizes utility function in case where all the three criteria are considered to be equivalent. Greater weight for the release leads to a minimum permissible level of $+782 \mathrm{~m}$, while greater weights for the water or the landscape quality lead to a minimum permissible level of $787-788 \mathrm{~m}$. It is also noticed that, in case of three equivalent criteria, utility function remains not far from its maximum value for a range of minimum permissible levels from $+782 \mathrm{~m}$ to $+788 \mathrm{~m}$.

The results of a multi-criteria analysis, given the methodological weaknesses and arbitrariness (Christofides et al 2005), help the delimitation of the problem; they can indicate a solution without determining it. It is clear from Figure 2 as well as from more 
analytical data (Research group 2002) that the choice of +780 m leads to non acceptable water and landscape quality, while choices of $+790 \mathrm{~m}$ and $+788 \mathrm{~m}$ lead to excessively low release with a relatively small environmental benefit. The choice of $+782 \mathrm{~m}$ leads to a non negligible landscape degradation for a significant part of the year and to a just acceptable water quality, while any violation of management rules will cause heavier environmental degradation; therefore, this choice cannot be accepted, at least for precautionary reasons. The only remaining acceptable choices are within the range 784$786 \mathrm{~m}$. Thus, following the variation of indices against minimum permissible levels, as shown in Figure 2, the optimal management recommendation has been to establish a desirable minimum permissible level of $+786 \mathrm{~m}$ and an acceptable minimum permissible level of $+784 \mathrm{~m}$.

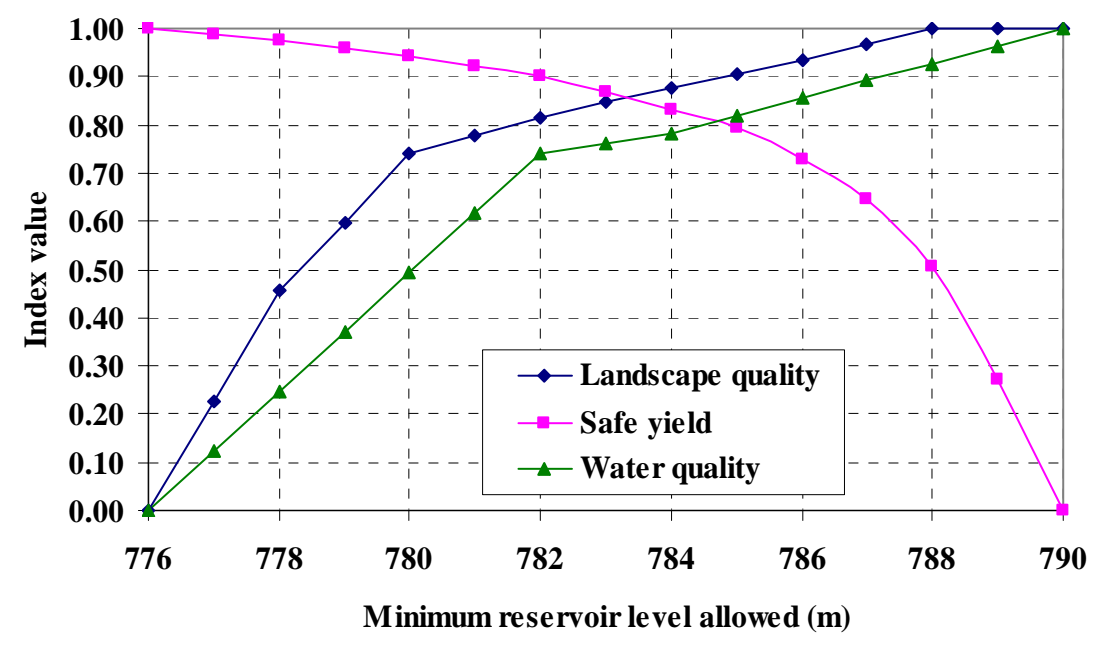

Figure 2. Indices of safe release, landscape and water quality against minimum permissible level

All the management instruments mentioned in the methodological part should be considered necessary for a rational management. In cases of competition between hydroelectric use and irrigation, the release program of the latter should be given priority; therefore, the annual water release will be realized in a non uniform way during the year, following mainly agricultural needs. This choice may not be the most efficient from the economic point of view; however it would be useful, because it may smooth protests from farmers and eventual negative social reactions against the proposed management.

\section{DISCUSSION AND CONCLUSIONS}

Ecosystems and the environment in general present a systemic behavior and their optimal management is a complex enterprise related to different physical constraints, human interests and values. The example of Plastiras lake indicates that rational management should include:

- Careful analysis of interactions between the system elements and identification of the factors of the social context or other important factors that may influence the system's responses

- Enrichment of the model system with qualitative and quantitative results when they are precise and objective

- Identification of more or less clear arbitrariness that may appear in the estimation of most parameters.

Quantification of parameters and model representation of a complex socio-environmental system constitute a problem that has to be considered in a realistic way (Levins 1968). The answer to questions on the Plastiras reservoir management cannot be based on illusions (Holling 1978) about expected model precision. It has been shown that most 
parameter estimations have had objective as well as arbitrary parts. However, the possibilities for stricter mathematical approaches of certain questions, for example the stochastic simulation of reservoir hydrological operation, in combination with simpler quantitative or qualitative approaches, for example the size of the dead-zone, can be utilised to support composite estimations, like the impact on landscape quality. Real limitations of some quantitative assessments have also been manifested; in fact, the calculations of water abstractions present a good precision; but one ultimate aim of management proposal is to support agricultural income related to irrigation, which cannot be calculated accurately. Similarly, estimations of impact on landscape present some uncertainty; but estimation of the corresponding loss of tourist income is even more uncertain. In conclusion, it seems important to optimize realism either of quantitative or of qualitative estimations and to introduce them objectively in the management proposal, taking account of key factors of the whole physical, social and legal framework.

The proposed management solution is subjected to comments from different directions. First of all, given that the range of possible values for the lake level extends from $+776 \mathrm{~m}$ to $+792 \mathrm{~m}$, it seems that the whole approach of criteria quantification and multi-criteria analysis has ended in proposing a minimum permissible level that is just the average of all possible values $(+784 \mathrm{~m})$.

Another question is about the reliability of the scheme based on the three selected parameters; it must be accepted that each one of the three criteria has its own importance, although it is related to different human values (Tress et al 2001). If the impact on water quality is underestimated (Christofides et al 2005), the case is simplified in a trade-off between water yield and aesthetics; a false picture is then created, where the agricultural productivity is put on one side and the "non quantifiable beauty" on the other, thus altering the nature of a complex problem.

A different way to establish the requested utility function would be to use a cost-benefit analysis, translating all criteria into monetary values. This is possible for hydroelectric use or even for drinking water supply, but more difficult for other uses. Environmental values are not easy to measure in monetary units (Bush 2003). Different methods, like "willingness to pay" or "hedonic price" have been discussed in the literature, but also criticized (Wenstop and Seip 2001, Christofides et al 2005). On the other hand, real monetary value of actual subsidized agricultural production is doubtful, while economic value of increasing tourist activities is probably significant but not easy to estimate and the question of tourist sustainability remains open.

Rationality of a management proposal, even based on sound scientific approach, does not ensure its success. Efficient implementation is mainly depending on actual equilibrium between opposite forces. However, appropriate scientific arguments can accelerate social processes; the development of local long-term material interests together with the consideration of cultural and legal aspects should gradually reveal the necessity of a more sustainable water management of Plastiras reservoir.

ACKNOWLEDGEMENTS: The project "Investigation of possibilities for management and protection of quality of the Plastiras Lake" has been supported by the NTUA and the Prefecture and Municipality of Karditsa.

\section{REFERENCES}

1. Andreadakis, A. C. Noutsopoulos and E. Gavalaki (2003). Assessment of the water quality of Lake Plastiras through mathematical modelling for alternative management scenarios, Proc. $8^{\text {th }}$ International Conference on Environmental Science and Technology, vol. A, 17-24, Lemnos, Greece.

2. Bush, M.B. (2003). Ecology of a Changing Planet, $3^{\text {rd }}$ edition, Prentice Hall.

3. Efstratiades A., Koutsoyiannis D., Sargentis G.-F., and Hadjibiros K. (2005). Resolving conflicting objectives in the management of the Plastiras Lake: Can we quantify beauty? Hydrology and Earth System Sciences, 9: 507-515. 
4. FILOTIS (2003). A database for the natural environment of Greece (www.itia.ntua.gr/filotis/)

5. Hadjibiros, K., D. Koutsoyiannis, A. Katsiri, A. Stamou, A. Andreadakis, G-F. Sargentis, A. Christofides, A. Efstratiadis and A. Valassopoulos (2002). Management of water quality of the Plastiras reservoir, $4^{\text {th }}$ International Conference on reservoir limnology and water quality, Ceske Budejovice, Czech Republic.

6. Hipel, K.W. (1992). Multiple objective decision making in water resources, Water Resources Bulletin, 28, 3-12.

7. Holling, C.S. (1978). Adaptive Environmental Assessment and Management, Wiley.

8. Levins, R (1968). Evolution in Changing Environments, Princeton University Press, New Jersey.

9. Popper, K.R. (1945). The Open Society and its Enemies, Routledge and Kegan Paul, London.

10. Research group (2002). Investigation of possibilities for management and protection of quality of the Plastiras Lake. Report of research programme, National Technical University of Athens, www.itia.ntua.gr (in Greek).

11. Sargentis, G-F., K. Hadjibiros and A. Christofides (2005a). Plastiras lake: the impact of water level on aesthetic value of the landscape, Proc. $9^{\text {th }}$ International Conference on Environmental Science and Technology, Rhodos, Greece, Vol B, 817-824.

12. Sargentis, G-F, K. Hadjibiros, G. Papagiannakis, E. Papagiannakis (2005b). Plastiras lake scenery: influence of the relief on the revelation of the water presence, Proc. $9^{\text {th }}$ International Conference on Environmental Science and Technology, Rhodos, Greece, vol B, 825-832.

13. Tress, B., G. Tress, H. Descamps, A.M. d'Hauteserre (2001). Bridging human and natural sciences in landscape research. Landscape and Urban Planning, 57, 137-141.

14. Wenstop, F. and K. Seip (2001). Legitimacy and quality of multi-criteria environmental policy analysis: a meta analysis of five MCE studies in Norway, Journal of Multi-Criteria Decision Analysis, 6, 65-76. 